\title{
Foot-and-Mouth Disease and Argentina's Beef Exports: The WTO's US-Animals Dispute
}

\author{
CHAD P. BOWN* \\ Peterson Institute for International Economics \& CEPR \\ JENNIFER A. HILLMAN** \\ Georgetown University Law Center
}

\begin{abstract}
This paper provides a legal-economic assessment of the WTO Panel Report in US-Animals, one of a growing list of WTO disputes arising due to problematic conditions under which an importing country closes and reopens its market after an infectious disease outbreak in an exporting country. The United States banned imports of beef from Argentina following a 2000 Argentine outbreak of highly contagious foot-and-mouth disease (FMD), a disease not found in the United States since 1929. The United States refused to relax its import ban, and Argentina filed a WTO dispute in 2012, more than six years after its last FMD outbreak. Our analysis starts with Argentina's claim that the gap between its first requests, in 2002, to restore its trading rights and no action by the United States as of 2012 constituted 'undue delay'. We rely on simple insights from economic research on asymmetric information problems - moral hazard and adverse selection - to describe the difficulties facing the World Organization for Animal Health (OIE) and the WTO's Sanitary and Phytosanitary (SPS) Agreement in dealing with problems like FMD. Such an environment creates disincentives for socially efficient behavior that were clearly realized in this episode. The exporting country has an incentive to hide information on outbreaks and report being disease-free too quickly, and the importing country has no incentive to quickly undertake the costly effort of conducting the necessary inspections to restore the exporter's market access. Finally, we address the Panel Report's treatment of alleged discrimination both across different FMD-impacted countries and across FMD-impacted and nonimpacted geographic zones within Argentina, and we touch on the Report's shift in approach regarding the obligation of the United States to take into account the special needs of developing countries such as Argentina.
\end{abstract}

\footnotetext{
*Email: cbown@piie.com

**Email: jah95@law.georgetown.edu

The authors acknowledge useful discussions with Carlo Cantorre, William Cline, Cullen Hendrix, Petros Mavroidis, Marcus Noland, Dan Sheesley, Ellen Terpstra, and participants at the European University Institute's WTO Case Law of 2015 Conference. All remaining errors are our own.
} 


\section{Introduction}

In 2001, the US Department of Agriculture (USDA) issued a regulation prohibiting the importation of fresh, chilled, or frozen beef from Argentina. The ban was motivated by outbreaks in Argentina of foot-and-mouth disease (FMD), a highly contagious virus that spreads quickly and causes significant pain, distress, and frequently death to animals that contract it. In 2012, roughly 11 years after the United States had closed its export market to Argentine beef, Argentina filed a request for consultations with the World Trade Organization (WTO) and launched a formal dispute. This paper provides a legal-economic assessment of the WTO Panel Report in the subsequent US-Animals dispute, which observed:

Given the virulence and the potential rapid spread of the disease, and the significant direct and indirect costs associated with eradication of an outbreak, most countries that have eradicated the disease impose strict sanitary measures on imports of animal products. ${ }^{1}$

While Argentina and many other countries have experienced FMD outbreaks in recent decades, the United States has not had a reported case since 1929. The United States maintains a ban on the importation of fresh meat and other animal products from cattle, sheep, goats, deer, and swine, as these are the species that are susceptible to the disease, from countries with FMD. ${ }^{2}$ Under US regulations, FMD is presumed to exist in all regions of the world except those declared to be free of the disease by the US Animal and Plant Health Inspection Service (APHIS), which is part of the USDA and is tasked with 'protect[ing] the health and value of American agriculture and natural resources'. ${ }^{3}$

US law permits imports from regions or countries that have not been declared free of FMD provided the regions comply with sanitary protocols agreed to with APHIS. For Argentina, the United States had set forth such protocols in 1997 via 9 CFR 94.21, which included conditions relating to the movement and slaughter of cattle and a requirement that 'FMD has not been diagnosed in Argentina within the previous 12 months'. In 1997-2001, the United States imported substantial volumes of Argentine beef pursuant to these protocols, but after FMD outbreaks in Argentina beginning in 2000, the United States repealed the protocols in 2001, leaving Argentine beef subject to the general prohibition on imports unless the region is declared FMD-free.

In 2002 and 2003, Argentina began requesting that the international community including the United States - reopen their markets to Argentine beef exports,

1 Panel Report, United States-Measures Affecting the Importation of Animals, Meat and Other Animal Products from Argentina, WT/DS447/R, 24 July 2015 (US-Animals).

2 In the US Code of Federal Regulations (CFR), see 9 CFR 94.1: 'Regions where rinderpest or foot-andmouth disease exists; importations prohibited'; an updated list of countries is published in APHIS (2016a).

3 APHIS (2016b) also states, as specific examples that motivate its mission, that 'if foot-and-mouth disease or highly pathogenic avian influenza were to become established in the United States, foreign trading partners could invoke trade restrictions and producers would suffer devastating losses'. 
claiming that it was again FMD-free. Such requests turned out to be premature; as Table 1 indicates, Argentina continued to experience FMD outbreaks until February 2006.

This dispute concerns the US repeal of 9 CFR 94.21, the US failure over many years to declare any regions of Argentina to be FMD-free, and Argentina's 2012 challenge to the US measures under the WTO's Agreement on Sanitary and Phytosanitary (SPS) Measures. ${ }^{4}$

The currently understood international standards for determining which areas of the world are free from diseases, like FMD, began in the early 1990s. At that point, the World Organization for Animal Health (OIE) received a mandate from its International Committee, composed of the delegates of OIE member countries, to draw up a list of member countries, or zones within countries, that would be officially recognized as free from four priority diseases: rinderpest, FMD, contagious bovine pleuropneumonia, and bovine spongiform encephalopathy (BSE). Each year, the disease-free status of member countries is reviewed by the OIE and, where appropriate, ratified and published. Argentina was on and off the OIE's FMD 'disease-free' list at various times during the period examined by the panel.

The rest of this paper proceeds as follows. Section 2 describes some of the salient economic issues underlying this dispute. We begin by describing the key export and import markets for beef during 1996-2015 to reveal both overall trends and how trade in these products can fluctuate due to economic shocks and disease-induced policy shocks. We then turn to the approach of economists to public policy problems associated with FMD by casting them as information asymmetry problems.

Section 3 begins our legal-economic assessment of the Panel Report. The first involves the timing of the US change in policy toward Argentine beef from regions that had been previously infected with FMD. The second addresses the responsibility for conducting inspections, once there have been repeated outbreaks and premature claims of disease eradication. We rely on a simple economic framework provided by research on information asymmetry problems to argue that the experience detailed in the Panel Report reveals that the OIE and SPS Agreement have not yet struck the right balance. In this case, they failed to incentivize both accurate information sharing - between exporting and importing country governments, regarding notification of the timing of disease outbreaks and their resolution - or to advise on an appropriate time for reopening a foreign market for international commerce once products were assured to be disease-free.

4 A number of related disputes involving claims under the SPS Agreement have been covered by contributions to this series: Horn and Weiler (2003), EC-Asbestos; Neven and Weiler (2006), Japan-Apples; Howse and Horn (2009), EC-Approval and Marketing of Biotech Products; Bown and Trachtman (2009), Brazil-Retreaded Tyres; Hoekman and Trachtman (2010), EC-Hormones; and Bown and Hillman (2016), India-Agricultural Products. While Argentina raised claims under Article I:1 and XI:1 of the General Agreement on Tariffs and Trade (GATT), the majority of its claims were SPS claims. The Panel, having found numerous violations of the SPS Agreement, exercised judicial economy and did not address the GATT claims. 
Elapsed time from Argentina's request to resume exports (Nov. 2002)
5 Feb. 2006

5 Jan. 2007

22 May 2007

15 Oct. 2008

26 Feb. 2009

27 Apr. 2009

30 Sept. 2009
Feb. 2009

Aug. 1997

Last outbreak of foot-and-mouth disease (FMD) in United States

United States authorizes importation of Argentine beef following a June 1997 risk assessment and rulemaking

Hundreds of outbreaks of FMD in various parts of Argentina

December 2001)

OIE recognizes Patagonia South as FMD-free zone

Argentina requests authorization to resume beef exports to United States

Meetings and exchanges of information between Argentine and US officials

OIE recognizes northern Argentina as FMD-free without vaccination

Argentina requests APHIS to recognize Patagonia as FMD-free

273 days (9 months)

Outbreak of Type O in province of Salta; OIE suspends FMD-free status

Numerous exchanges of information between APHIS and Argentina's SENASA, number of US

visits to Argentina

OIE confirms recognition of Patagonia South as FMD-free without vaccination

Last outbreak of FMD (in province of Corrientes) noted in the Panel record

APHIS publishes proposed rule in Federal Register to change disease status of Patagonia South to

FMD-free; beginning of 60-day comment period

OIE reinstates FMD-free status of Northern Argentina and Patagonia North

APHIS proposed site visit in December 2008

APHIS site visit to Patagonia

2009 Omnibus Appropriations Act passes Congress with language: No funds can be used for any activity that would allow the importation of meat from Argentina; calls for report to House and Senate Appropriations Committees

APHIS sends SENASA letter stating that no additional information was required to proceed with APHIS rulemaking

2009 Omnibus Appropriations Act expires
1,179 days

1,512 days ( 4 years and $1+$ month) 
Summer $2010 \quad$ Letters exchanged between APHIS and SENASA

30 June 2011 US statement before WTO SPS Committee that APHIS had 'completed the risk analysis regarding

3,150 days ( 8 years and $7+$ months) the region north of the $42^{\text {nd }}$ parallel and would subsequently draft a proposal to allow importation of beef under certain conditions'.

19 Oct. 2011 US statement before SPS Committee that APHIS had 'completed the assessment and was drafting a proposal to allow the importation of beef under conditions'.

30 Aug. 2012 Argentina requested consultations about the US ban on its beef exports

3,261 days ( 8 years and $11+$ months) Argentina requested the establishment of a Pane

6 Dec. 2012

28 Jan. 2013

24 July 2015

WTO Dispute Settlement Body established the Panel

31 Aug. 2015

Final Panel Report circulated

Panel Report adopted

4,673 days (12 years and 9+ months)

Source: Compiled by the authors from the WTO Panel Report and minutes of the SPS Committee.

APHIS = US Animal and Plant Health Inspection Service; OIE = World Organization for Animal Health; SENASA = Argentina's Servicio Nacional de Salud

Animal; SPS = sanitary and phytosanitary. 
Section 4 turns to other topics raised in the Panel Report. These include the question of discrimination across FMD-impacted countries and most-favoured-nation (MFN) treatment, as well as discrimination within Argentina in order to tackle the question of regionalization. We also briefly comment on the apparent shift in willingness to place more substantial obligations on developed countries to take into account the special needs of developing countries. Section 5 concludes.

\section{The economics of beef markets and national FMD policies}

This section describes the international trade flows of beef at issue in this dispute and market failures at the national level due to diseases such as FMD.

\subsection{The United States' import market for beef and Argentina's exports of beef}

In 2015, the United States imported over \$6 billion in fresh, chilled, or frozen beef products. In real terms, as Figure 1 illustrates, US beef imports were more than 3.5 times higher in 2015 than in 1996. However, these imports also exhibited fluctuations during this period; the US beef-producing industry itself experienced negative shocks, including four outbreaks of BSE between 2003 and 2012. ${ }^{5}$ The fact that various foreign markets were therefore closed to US beef exports also likely contributed to the political efforts of the National Cattleman's Beef Association between 2003 and 2015 to discourage lifting the ban on imports from Argentina.

US beef imports have also fluctuated in some years in ways that can be tied to major economic or animal health shocks, at both the bilateral and multilateral levels. For example, total US imports of beef dipped in 2003 partly because of a BSE outbreak in Canada that led to a temporary US bilateral import ban; imports from Canada increased in 2004 as the ban was lifted.

Furthermore, the real value of US beef imports fell by $10 \%$ in both 2008 and 2009 during the trade collapse associated with the global economic crisis. US beef imports rebounded strongly shortly thereafter and grew by $138 \%$ between 2009 and 2015 .

As Figure 2 illustrates, over 92\% of US beef imports in 2015 derived from only four countries: Australia, Canada, New Zealand, and Mexico. Of these, Canada's share of the US import market has declined considerably - from a peak of $48 \%$ in 1999 to only $17 \%$ in 2015.6 New Zealand's market share has remained relatively

5 This likely had at least two offsetting effects on the US beef market. In certain years, US production was down because of BSE, and this served to boost import demand for foreign beef. On the other hand, a number of foreign markets remained closed to US beef exports during this period, leaving US beef to be sold in local markets, with a consequent dampening of demand for US imports.

6 Canada's declining share of the US import market may be associated with several factors, including liberalization of the US market for live animals (cattle) that has resulted in some reorganization of the North American beef supply chain. Furthermore, the US country of origin labeling regulation for meat products, imposed between 2009 and 2015 (Bown and Brewster, forthcoming; Greene, 2015), likely increased US meatpackers' costs and thus contributed to an increase in US import demand over the period (Figure 1). 
Figure 1. Total US beef imports, 1996-2015

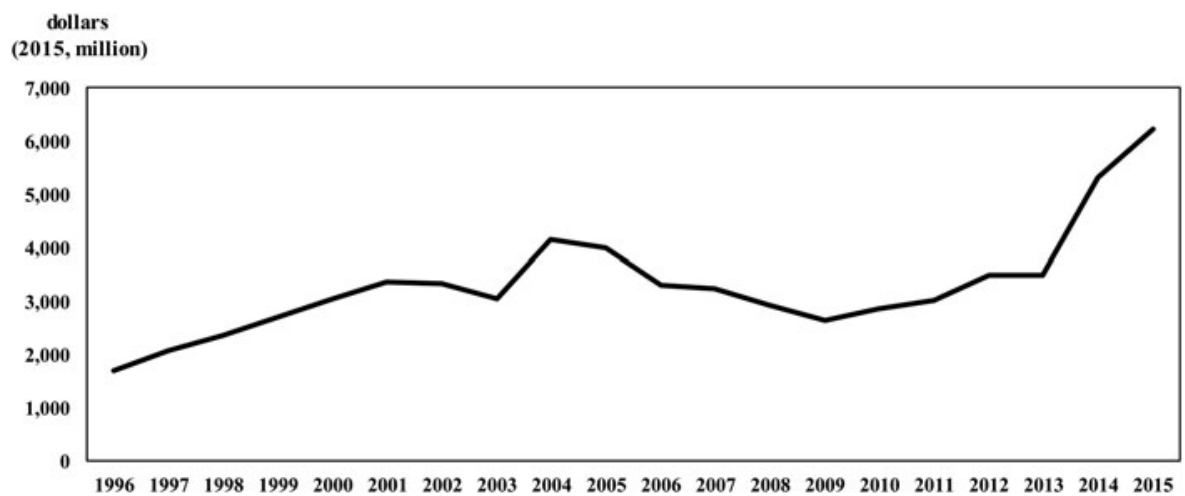

Source: Constructed by the authors with data from USITC Dataweb for fresh and chilled beef (HTS 0201) and frozen beef (HTS 0202).

Figure 2. Shares of the US import market for beef, selected countries, 1996-2015

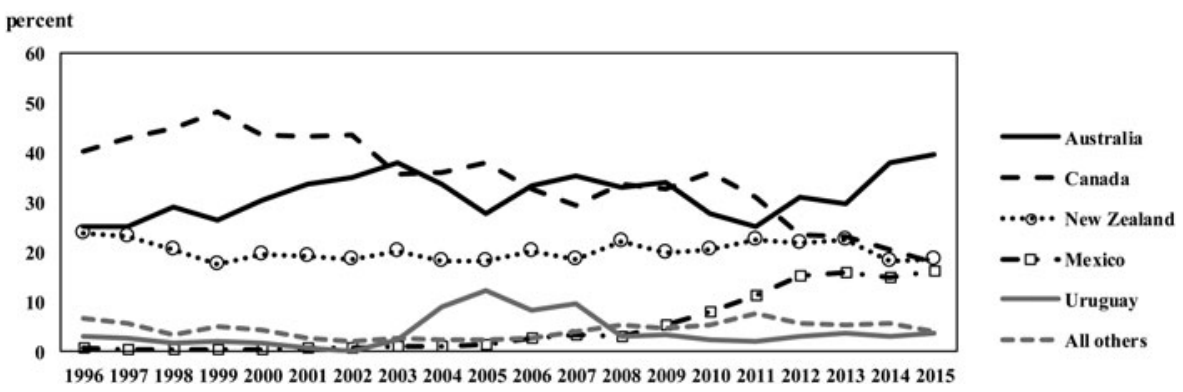

Source: Constructed by the authors with data from USITC Dataweb for fresh and chilled beef (HTS 0201) and frozen beef (HTS 0202). US import share from Argentine during this period included in 'All Others' but not shown independently since so small. See Figure 3.

constant, while Mexico and Australia have increased their share of the US import market. This may be partially explained by the US implementation of free trade agreements that lowered bilateral beef tariffs and expanded the quantitative limits of the tariff rate quotas for selected countries. Nevertheless, the fact that countries at great geographic distance from the United States-e.g., Australia and New Zealand-make up such a sizable share of the US import market indicates that beef need not be a geographically privileged product. Thus, it may be possible for Argentina to successfully export beef to the United States under the right conditions. ${ }^{7}$

7 It is also worth noting that Argentine beef tends to be grass-fed and thus has a different taste profile from most US beef, which is a heavily grain-fed product. High-value beef cuts could command a sufficient price premium to overcome any geographic disadvantage of distance from the US market. 
Figure 3. US imports of beef by selected source country in Latin America, 19962015

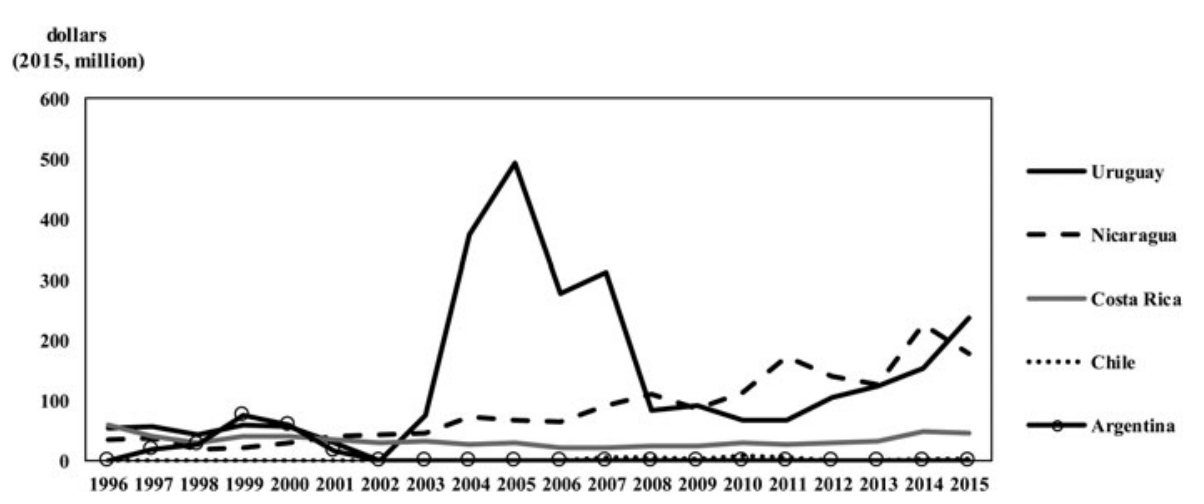

Source: Constructed by the authors with data from USITC Dataweb for fresh and chilled beef (HTS 0201) and frozen beef (HTS 0202).

Figure 3 illustrates US imports of beef from several smaller countries in Latin America, including considerable beef imports from Costa Rica and Nicaragua. Furthermore, despite an FMD outbreak that cut Uruguay's exports to the United States to zero in 2002, US imports of beef from this country rebounded to more than $\$ 200$ million by 2015 . Finally, US imports from Chile - another country mentioned in the dispute described below - have remained negligible, despite the fact that Chile has been determined FMD-free.

As Figure 3 also documents, US beef imports from Argentina peaked at roughly $\$ 75$ million (in 2015 constant dollars) in 1999, when Argentina accounted for $2.7 \%$ of the US beef import market. The Argentina FMD outbreak that triggered the US import ban in 2001 cut Argentina's exports to the United States to zero by 2002. Argentina's 'loss' of $\$ 75$ million in annual exports to the United States is comparable to the average change in trade flows in disputed products between complainants and respondents as measured across all WTO disputes (surveyed in Bown and Reynolds, 2015, table 3). By itself, this suggests there is nothing unusual about Argentina's complaint. Finally, Figure 3 also demonstrates the limited impact of the recent (effective as of October 2014 for Patagonia and September 2015 for Northern Argentina) post-WTO Panel decisions by the United States to reauthorize beef imports from Argentina.

Figure 4 shows Argentina's exports of beef to the world and certain foreign markets during this period. After the FMD outbreak that began in 2000, Argentina's total beef exports fell $80 \%$ from two years earlier and bottomed out at roughly $\$ 150$ million in 2001. Once the FMD was addressed and the OIE recognized part of Argentina as FMD-free, Argentina's global beef exports quickly responded, peaking at nearly $\$ 1.7$ billion in 2009 , although they have declined considerably since then, partially due to Argentina's own imposition of export restrictions. 
Figure 4. Argentina's exports of beef, total and by selected destination market, 1996-2015

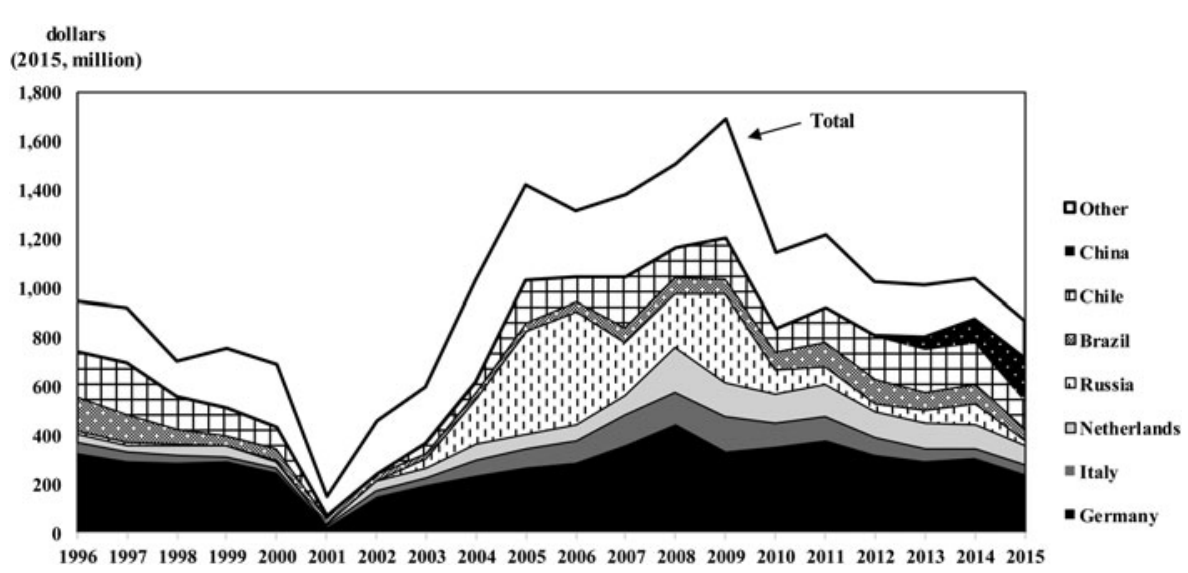

Source: Constructed by the authors with data from UN Comtrade for fresh and chilled beef (HS 0201) and frozen beef (HS 0202). Argentine exports to United States not shown; see Figure 3.

Some of the key foreign markets for Argentina's beef exports may help to explain its frustration with the US pace of addressing its request to resume bilateral exports. Specifically, Figure 4 shows that in some years since the FMD outbreaks, highincome EU countries such as Germany, Italy, and the Netherlands together accounted for roughly $50 \%$ of total Argentine beef exports-e.g., exports to these countries alone were $\$ 750$ million in 2008 .

Similarly, some important beef export markets for Argentina during this period were other emerging economies, although trade with these markets was characterized by considerable volatility. For example, the share of Argentina's exports to Chile and Russia peaked at 23\% in 1997 and 35\% in 2006, respectively; in other years, those markets accounted for single-digit shares of Argentina's beef exports. Most recently, Argentina has enjoyed major export growth to China. As late as 2011, Argentina's beef exports to China were zero; by 2015 they were $\$ 170$ million, or $20 \%$ of Argentina's total beef exports.

\subsection{Market failures, information asymmetry problems due to FMD, and national policies}

We now consider a simple, closed-economy model designed to represent Argentina's domestic market for beef in the presence of FMD. In such a model, FMD is a negative externality because an outbreak in one farmer's herd generates costs to others because the disease is so infectious - an outbreak could easily spread to other farmers' cattle and impose losses on those farmers. The FMD externality indicates that, if unabated by government policy, market failures are likely. Thus, 
there is a potential efficiency-enhancing role for national governments to design and implement policies to address FMD. ${ }^{8}$

Economists typically consider the problems associated with FMD as arising from two essential characteristics: (1) an FMD outbreak is assumed to occur with some positive probability, and (2) when an FMD infection occurs, only sometimes is this information known to authorities.

First, FMD does indeed occur with some positive probability, but the nature of the disease implies that farmers can reduce its likelihood if they undertake costly investment in biosecurity measures, such as limiting herd movement, reducing exposure to outside contaminants, and cleansing and disinfecting the premises. However, since not all benefits of these measures accrue to the farmer - i.e., one farmer's effort to thwart a potential FMD outbreak provides externality benefits to other farmers - an individual farmer will tend to invest in prevention only to the extent that it makes sense from a private (profit-maximizing) perspective. The existence of investment benefits that spill over beyond the farmer into society implies that markets on their own will fail unless governments intervene with the appropriately tailored policy.

The government could legally mandate that the farmer undertake such biosecurity investment measures, or it could incentivize them through subsidies. However, a separate well-known real-world problem arises when governments implement such policies: the information asymmetry associated with the farmer's effort to 'comply' with the policy. How does the government know whether the farmer is following the biosecurity protocols? Government monitoring of individual farmers to prevent shirking is too costly. In economics, this information asymmetry leads to what is called a 'moral hazard' (hidden action) problem.'

Second, it is possible that some FMD episodes go undiscovered by anyone aside from the farmer. Certainly, the farmer is in the best position to observe and report occurrences of the disease, and the sooner it is reported to the government, the more quickly the outbreak can be contained and the costs limited. However, again, market failure may result from the divergence between social costs and the private costs to the farmer depending on whether and how quickly the outbreak is reported. If the outbreak of FMD is reported, the farmer will experience losses to the herd with certainty, as authorities would mandate the herd is culled. If the

8 This section draws heavily from Wolf (2013), which provides a very useful introduction to the economic incentive problems facing policymakers in the event of infectious disease outbreaks affecting cattle. Motivation for the indemnity policy discussion that follows is Argentina's Servicio Nacional de Salud Animal (SENASA)'s issuance of indemnity payments to farmers during the period of this FMD outbreak; Rich (2005: 12) provides a discussion.

9 The classic example of moral hazard arises in the design of car insurance. If the car is fully insured, and since the driver's actions cannot be perfectly monitored, a driver has insufficient incentive to park it in a safe area or to avoid accidents. A solution to the problem was for insurers to issue deductibles, so that some of the risk burden was shifted back to the driver and would thus induce the driver to engage in behavior jointly beneficial to the driver and the insurer. 
outbreak is not reported, there is a chance the disease will not spread and that it will go undetected by the authorities. If so, the losses will be smaller - e.g., perhaps only partial loss of a herd. However, if the farmer does not report the FMD outbreak, there is greater chance that it will spread and impose greater costs to society.

In the absence of any policy intervention, the market equilibrium outcome of this problem would result in the farmer's underreporting suspected cases of FMD because the failure to notify FMD imposes costs to society (FMD outbreaks on other farms) larger than the private costs to the individual farmer. In economics, this information asymmetry leads to what is called a problem of 'adverse selection' (hidden information). ${ }^{10}$

Economists typically implement a 'principal-agent' framework to evaluate the implications of policies designed to address the economic incentives created by such information asymmetries. The government (the principal) represents the national or societal interest and seeks to design a policy that would incentivize the farmer (the agent) to act in society's best interest, as opposed to the farmer's interest alone.

Gramig, Horan, and Wolf (2009) developed a formal model that includes both types of information asymmetries to examine the tradeoffs associated with FMD. In particular, they examined the implications of a government indemnity payment program, which is a policy that guarantees to pay a farmer a set price in the event that the farmer truthfully reports an outbreak of FMD. One critical element is the size of the guaranteed payment relative to the expected costs to the farmer of the lost herd due to the government response (e.g., culling) and lost business once the FMD outbreak is publicized.

Their baseline analysis reveals two offsetting effects of a guaranteed indemnity payment program. First, a higher guaranteed payment encourages farmers to report the outbreak of FMD; this helps to address the adverse selection problem. But, second, a higher payment decreases the incentive for farmers to undertake the biosecurity investment necessary to prevent an FMD outbreak in the first place. Because the farmer is more likely to be fully compensated for an FMD outbreak, the higher guaranteed payment exacerbates the moral hazard problem. Put differently, a lower guaranteed indemnity payment addresses the moral hazard problem by placing more of the burden on the farmer to invest in biosecurity, but it also suggests that the farmer is less likely to report an FMD episode. The

10 The classic example of adverse selection arises in the market for used cars and is referred to as the 'lemons' problem (Akerlof, 1970). The information asymmetry problem in the used car market is that buyers cannot tell whether the vehicle being offered to them is high quality or low quality (a lemon). Because of this unobservability, the consumer offers a price that is the average between the low- and high-quality cars. But since this price is less than the valuation of the high-quality car, sellers of highquality cars may exit the market. Thus, the only market transactions that occur end up being for lowquality cars. 
low payment increases the incentive for the farmer to try to conceal the outbreak, and the adverse selection (hidden information) problem is exacerbated.

One of the important insights of the Gramig-Horan-Wolf approach is that when there are two separate information asymmetry problems - as in the national context with FMD - a 'one-size-fits-all' public policy of a single indemnity payment scheme does not provide the government enough firepower to create the right incentives for farmers. The authors show that access to a second policy to complement the indemnity - such as an appropriately sized fine for failure to report a disease - is required if the goal is to elicit the societally appropriate levels of both farmer biosecurity investment and FMD reporting.

It is clear from the US-Animals dispute, as we detail below, that Argentina's public policy was not able to quickly or effectively deal with its FMD outbreak. The episode revealed problems with both Argentina's investment in biosecurity and truthful, accurate, and timely reporting. Nevertheless, it is also clear that the Panel Report itself was not directly concerned with Argentina's ex ante design or ex post implementation of its indemnity payments or other public policy toward FMD. The Panel was tasked with evaluating the US failure to reopen its market to Argentina's beef exports.

The Gramig-Horan-Wolf model highlights how information asymmetries created by the possibility of an FMD outbreak pose significant challenges for the design of not only national but also global policies. There is an important role for the OIE and the WTO's SPS Agreement to address the incentives faced by importing and exporting countries, as well as the exporting country's domestic policies, in order to motivate prompt and accurate reporting.

\section{Legal-economic analysis: undue delay and the burden of proof}

This section provides our assessment of the concerns arising in the Panel Report for US-Animals. Table 2 summarizes the legal elements in the dispute and the Panel's key determinations.

\subsection{The timing of US market reopening and the issue of undue delay}

Argentina's first major contention in the 2012 dispute was that the US delay in responding to Argentina's request to resume import protocols for beef from Northern Argentina and for recognition of Patagonia as FMD-free was 'undue' and therefore violated the WTO's Agreement on Sanitary and Phytosanitary Measures. In particular, annex $\mathrm{C}(1)(\mathrm{a})$ of the SPS Agreement requires that an importing country's control, inspection, and approval procedures be 'undertaken and completed without undue delay and in no less favorable manner for imported products than for like domestic products'. As additional context, Argentina also claimed that it was discriminated against, given that the United States took only two years to approve imports from Uruguay after its last outbreak of FMD, 
Table 2. Legal elements of US-Animals

\begin{tabular}{|c|c|c|}
\hline SPS agreement provision & Claims by parties & Panel determination \\
\hline $\begin{array}{l}\text { Article } 8 \text { and annex } \mathrm{C} \text { - requirement to } \\
\text { complete procedures without 'undue } \\
\text { delay' }\end{array}$ & $\begin{array}{l}\text { Argentina: Nearly } 10 \text { years to process request to resume } \\
\text { imports is 'undue' } \\
\text { US: Argentina outbreaks and failure to provide information } \\
\text { caused some of delay }\end{array}$ & Violation of article 8 and annex C; delay was undue \\
\hline $\begin{array}{l}\text { Article } 3.1 \text { - requirement to base mea- } \\
\text { sures on international standards (i.e., } \\
\text { OIE Terrestrial Code) }\end{array}$ & $\begin{array}{l}\text { Argentina: US measure not based on OIE guidelines for } \\
\text { imports from FMD-free regions (w/ or w/out vaccinations) } \\
\text { US: OIE designation of region as FMD-free is not 'inter- } \\
\text { national standard' per } 3.1 \text { of SPS Agreement }\end{array}$ & $\begin{array}{l}\text { Violation of } 3.1 \text { and } 3.3 \text { : OIE permits trade in beef from } \\
\text { countries in which vaccination against FMD occurs; did } \\
\text { not reach whether OIE recognition is international stand- } \\
\text { ard; violation of } 3.3 \text { because violation of Article } 8 \text { and } \\
\text { annex C, 5.1, } 2.2,5.6,2.3,6.1 \text {, and } 1.1\end{array}$ \\
\hline $\begin{array}{l}\text { Article } 5.1 \text { and Article } 2.2 \text { - require- } \\
\text { ment for a risk assessment }\end{array}$ & $\begin{array}{l}\text { Argentina: No risk assessment was done; if no risk assess- } \\
\text { ment was done, automatic violation of } 2.2 \text {; US } \\
\text { Appropriate Level of Protection (ALOP) not clear and } \\
\text { varies by country } \\
\text { US: } 2001 \text { regulations (ban) based on risk assessment } \\
\text { OIE: FMD extremely dangerous and contagious; before } \\
\text { trade, importing country must be satisfied that its animal } \\
\text { health status will be adequately protected }\end{array}$ & Violation of $2.2 \mathrm{~b} / \mathrm{c}$ violation of 5.1 ; no risk assessment \\
\hline $\begin{array}{l}\text { Article } 5.4 \text {-ALOP should take into } \\
\text { account objective of minimizing } \\
\text { negative trade effects }\end{array}$ & $\begin{array}{l}\text { Argentina: US has no coherent ALOP } \\
\text { US: article } 5.4 \text { is not mandatory }\end{array}$ & No finding $\mathrm{b} / \mathrm{c}$ no affirmative obligation in article 5.4 \\
\hline $\begin{array}{l}\text { Article } 5.6 \text { - requirement that mea- } \\
\text { sures not be more trade restrictive } \\
\text { than necessary }\end{array}$ & $\begin{array}{l}\text { Argentina: US could have used OIE TC or } 9 \text { CFR } 94.22 \\
\text { which is less trade restrictive } \\
\text { US: insufficient evidence for less restrictive alternative; OIE } \\
\text { TC not OK b/c US doesn't accept vaccination }\end{array}$ & Violation: US could have used protocols in 9 CFR 94(1)(a) \\
\hline
\end{tabular}


Table 2. (Cont.)

SPS agreement provision

Claims by parties

Panel determination

Article 2.3 - requirement not to discriminate arbitrarily between WTO Members

Argentina: US permits imports from Uruguay but not Northern Argentina, from Santa Catarina and Chile but

Violation: discrimination against Northern Argentina and Patagonia vs. Uruguay, Santa Catarina, and Chile not Patagonia

US: regions are different; Argentina intentionally kept out-

breaks confidential

Article 6.1 - requirement to adapt Argentina: US required to recognize Patagonia as FMDfree, OIE had already recognized

US: still in process of adapting to regional conditions at time of Panel request

Article 10.1 - requirement to take into Argentina: US should make doing risk assessment for account special needs of developing countries

Article 1.1 - SPS measures should be applied in accordance with SPS

Agreement

Argentina as a developing country a priority

US: does take developing status into account

Argentina: if US import restriction violates other provisions of SPS Agreement, then violates article 1.1

US: no response

Argentina: MFN violation

Violation: undue delay and failure to adapt to regional conditions

GATT Article I - MFN

Argentina: ban on imports is quantitative limit

GATT Article XI.1 - no quantitative restrictions

Notes: APHIS = US Animal and Plant Health Inspection Service; $\mathrm{b} / \mathrm{c}=$ because; $\mathrm{CFR}=\mathrm{US}$ Code of Federal Regulations; GATT = General Agreement on Tariffs and Trade; OIE = World Organization for Animal Health; SENASA = Argentina's Servicio Nacional de Salud Animal; SPS = sanitary and phytosanitary; TC = OIE Terrestrial Code. 
while Argentina's approval had not been considered at the time of the establishment of the Panel, nearly seven years after its last FMD outbreak. ${ }^{11}$

The United States, in turn, pointed to several factors contributing to its delay: Argentina's Servicio Nacional de Salud Animal (SENASA's) slow responses to requests for information, changes in Argentina relating to surveillance regulations and slaughterhouse standards, time needed to respond to the FMD outbreaks, a SENASA labor strike in 2005, and US laws on regulatory flexibility and paperwork reductions.

The arguments and the Panel's analysis raise several questions. What is the appropriate benchmark for measuring what constitutes 'undue' delay? If any errors or delays have occurred in the exporting country, do they necessarily justify further delays by the importing country? If there has been political interference in the process, is that an automatic violation of annex C of the SPS Agreement?

At the outset, the Panel noted the US claim that not every delay in undertaking or completing an approval procedure is contrary to the provisions of annex $\mathrm{C}(1)(\mathrm{a})$. The Panel also noted the US claim that the length of the approval process for Argentine exports conducted by other WTO members is not a reliable benchmark. Instead, the Panel accepted the interpretation in EC-Approval and Marketing of Biotech Products that a 'delay' is 'a period of time lost by inaction or inability to proceed' and noted that OIE guidelines and the US APHIS standard processing times serve as important indicators of a reasonable length of time (para. 7.117). ${ }^{12}$

The Panel then engaged in a two-part analysis. First, it determined that there were delays both in the approval process for permitting beef imports from Northern Argentina and in the process of granting FMD-free status to Patagonia. Second, to assess whether the delay was 'undue' - i.e., unwarranted, excessive, disproportionate, or unjustifiable - the Panel examined each US justification. It concluded that three of four periods of delay were not justified, but that one was, given SENASA's delay in providing information in response to reasonable US requests. For one period (the time between the proposed rule to permit imports and promulgation of the final rule), the Panel assessed whether a period of more than one and a half years was reasonable. The Panel noted that it took APHIS only between four and 13 months to assess whether to permit imports from Uruguay, Santa Catarina (a state in southern Brazil), and Japan, and concluded that a period of over one year was 'neither ordinary nor expected' (para. 7.154). The Panel faulted the United States for a process that falls outside of the 'ordinary'

11 The arguments were slightly different for exports from Northern Argentina versus those from Patagonia. For Northern Argentina, the request was simply to reinstate Argentina's 1997-2001 privileges to export pursuant to specific protocols because much of the scientific work was done prior to 1997 and no outbreaks had occurred since 2006. For Patagonia, the request was to declare Patagonia (both North and South) FMD-free, based on the fact that there had been no FMD outbreaks in Patagonia South since 1976 and the OIE had continuously recognized it to be FMD-free since 2002, while Patagonia North had not had an outbreak since 1994 and had been declared FMD-free by the OIE since 2007.

12 Panel Report, EC-Approval and Marketing of Biotech Products, WT/DS291/R, 29 September 2006, para. 7.1495 
while recognizing that APHIS does not have a clearly articulated timeline by which to judge its determination. The Panel may have been influenced by the United States' having taken no action to reopen to Argentine beef imports during nearly 13 years since Argentina's initial November 2002 request.

A further source of comfort to the Panel appears to come from its perception that APHIS may have slowed its process due to political pressure from the US Congress. In 2009, Congress passed the Omnibus Appropriations Act, which prohibited the payment of salaries or expenses of any person for any activities that would allow imports of meat from Argentina until the US Secretary of Agriculture had reviewed US animal health aspects of the proposal to permit Argentine imports and issued a report to the Congress on his findings. Argentina consistently pointed to the passage of this act as evidence that the delay was not supported by scientific considerations but rather was due to political pressure on APHIS.

\subsection{Burden of proof}

This dispute revealed a clear tension inherent in the SPS Agreement concerning the allocation of the burden of proof. The SPS Agreement places the burden on the importing country. Yet, in this episode, Argentina was required to demonstrate the absence of FMD, the maintenance of effective surveillance techniques, and the ability to sequester the disease to prevent its spread across regions. On the other hand, US law required that the United States rely on its own procedures, including its own on-site inspections, to determine that Argentina had met these requirements.

The SPS Agreement was brought into the WTO as part of the Uruguay Round's 'single undertaking'. Only 43 contracting parties had signed the Tokyo Round's Standards Code, which contained pre-WTO disciplines on SPS measures. ${ }^{13}$ The new SPS Agreement stemmed in part from the perception that the Standards Code had failed to prevent disruptions of trade in agricultural and other food products and that the standards were too widely divergent across countries. The new SPS Agreement became binding on all WTO members.

The SPS Agreement places the initial burden on importing countries that impose SPS measures, requiring that such measures be based on scientific principles; be applied only to the extent necessary to protect human, animal, or plant life or health; and not discriminate arbitrarily or unjustifiably between members. But this means that countries wishing to export must have in place their own internal SPS systems, and maintain sufficient records and administrative support to demonstrate that their agricultural products are in compliance with all the requirements of the importing member's SPS measure. Thus, although the SPS Agreement and its annex $\mathrm{C}$ place the burden for control, inspection, and approval on the importing member, an extensive burden also falls on the exporting country. And the

13 For a discussion of the history of the SPS and technical barriers to trade (TBT) agreements and their relationship to the GATT, see Marceau and Trachtman (2006). 
burden can effectively shift from the importing country to the exporting country after the outbreak of a contagious disease.

Argentina and the United States both bore some of the burden for conducting a risk assessment in 1997, long before the more recent FMD outbreaks and WTO dispute. They worked in the 1990s to craft mitigating protocols to bring imports of Argentine beef into compliance with US standards for protection against FMD, with Argentina required to continually certify that its exports met the requirements and to notify the United States (and the OIE) of any outbreaks. The risk assessment and protocol opened up the US market to Argentine beef between 1997 and 2001. As shown in Figure 3, US imports of beef from Argentina achieved a peak of $\$ 75$ million during this period.

When cattle from neighboring countries were illegally imported into Argentina and outbreaks of FMD began occurring in 2000, the United States banned further imports and effectively shifted the burden to Argentina to prove that it was able to control the disease. Argentina requested that APHIS come for site visits, in both Patagonia and Northern Argentina, and was required to provide extensive information and data both before and after each of five site visits between the fall of 2000 and February 2009. ${ }^{14}$ There were often long intervals between the visits, despite repeated requests by Argentina, as the visits were a prerequisite to be declared FMD-free and to approval to resume beef exports. Yet Argentina's initial request in November 2002 may have been premature. It sought authorization to export beef to the United States pursuant to the 1997 protocols - even as sporadic outbreaks of FMD continued, particularly in Northern Argentina, until 2006.

This dispute also raises questions about the burden borne by exporting countries and the incentives associated with costs for both compliance and inspection. The United States incurred a significant burden to perform a full risk assessment while promulgating a final rule in 1997 to permit the initial imports of Argentine beef. That rule was clearly tied to US commitments as part of the Uruguay Round and the adoption of the SPS Agreement in 1994. ${ }^{15}$ The rule was preceded by site visits to Argentina, the promulgation of a proposed rule to permit Argentine imports, a 150-day comment period, four public hearings in four cities throughout the United States, and responses to the 113 comments received. ${ }^{16}$ The final rule was

14 The site visits noted in appendix 1 of the Panel Report of US-Animals were: (1) 27 September-6 October 2000, APHIS and OIE staff visited to gather information for a risk assessment after a number of outbreaks; (2) 1-5 December 2003, APHIS and the Canadian Food Inspection Agency conducted a site visit in Patagonia; (3) 30 May-3 June 2005, APHIS conducted a site visit in Northern Argentina; (4) 6-8 September 2006, APHIS visited the areas affected by FMD outbreaks; and (5) 23-26 February 2009, APHIS conducted a site visit to Patagonia.

15 The background to the final rule states: 'In proposing the amendment to the regulations [to permit imports from Argentina], we stated that we considered the proposed regulatory changes to be consistent with and to meet the requirements of international trade agreements that had recently been entered into by the United States'; 62 Federal Register (FR) 34385 (26 June 1997).

16 See 62 FR 34385-34394 (26 June 1997) and 61 FR 16978-17105 (18 April 1996). 
accompanied by an assessment of the economic impact of permitting imports from Argentina and contained certain 'mitigating measures', including that the meat had to come from premises where FMD had not been present during the prior 12 months and where the cattle had not been vaccinated for FMD (which masks the symptoms), and that all bone and lymphoid tissue was removed before exportation.

After more than 2,000 FMD outbreaks in Argentina in 2000 and 2001, how many of these steps should the United States be required to undertake all over again? Viewed differently, what should Argentina be required to do before requesting renewed access to the United States? The SPS Agreement does not address the issues, other than annex C's general placement of the burden for control, inspection, and approval on the importing country and its requirement that any fees for procedures performed not discriminate between domestic and imported products.

Both sides attempted to use the 1997 ruling to their advantage. Argentina claimed that little had to be done to reinstate its previous status, since so much work had gone into the 1997 final rule. The United States contended that its delays were justified by the substantial new data and extensive new work required in light of the thousands of FMD outbreaks.

Argentina also urged reliance on the OIE's various recognitions of regions in Argentina as FMD-free as grounds to claim that the United States did not need to start its assessment from scratch. Clearly, reliance on the OIE as an independent international organization responsible for health standards for international trade in animals and animal products could be a cost-effective solution to the current allocation of the burden to importing countries. But, as this case demonstrates, importing countries are likely to be highly resistant to ceding control over inspection or approval procedures. Moreover, the OIE typically does not perform an on-site inspection itself; its information dissemination role depends on the data and responses to questions typically submitted by the exporting country. As we explained in Section 2, the existence of information asymmetries even only at the national level - between farmers and the government - can lead to significant market failures.

The United States regards OIE approval as, at best, a prerequisite for placing a country or region on its list for potential site visits. The United States generally does not grant approval for imports after a disease outbreak without completing its own site visit and verification of data and control procedures submitted by the exporting country.

\subsection{Generating the right economic incentives in light of information asymmetries}

The OIE is an international standard-setting organization supported by its 180 member countries. It provides a global public good. ${ }^{17}$

17 For an introduction to and discussion of the OIE's general, global public good-provider role related to trade in animal products impacted by infectious diseases, see Bown and Hillman (2016). 
Consider again the basic information asymmetry problem between the Argentine government and its farmers described in Section 2. The OIE supports member country governments that seek to design and implement efficient and effective national policies to address FMD. An important OIE role is to help Argentina's government incentivize farmers to invest in biosecurity measures to reduce outbreaks while also encouraging them to report outbreaks expeditiously when they occur.

However, this dispute reveals that the environment created by the OIE and the SPS Agreement has not struck the right balance to ensure that foreign markets reopen in an appropriate and timely manner after an FMD outbreak. Two major concerns stand out.

Argentina lacked credibility in truthfully reporting information. The Panel Report (appendix 1) notes that SENASA 'out of concern for maintaining the international status of exports ... decided to keep the FMD situation confidential until further data would permit a better evaluation of the situation'. Moreover, in July 2003 the OIE faced a request by Argentina to recognize as FMD-free Northern Argentina, where vaccination is practiced, only to suspend the designation one month later because of new outbreaks. This suggests that current OIE incentives are not sufficient to prevent Argentina (or any country) from claiming 'too early' that it was FMD-free. In addition, the United States was sceptical of Argentina's ability to control the movement of cattle or beef internally and at the border with its neighbors. The United States claimed that Argentina kept changing the rules on what could cross the line between Patagonia and Northern Argentina, as Argentina claimed each time that Patagonia had been effectively isolated from the outbreaks in Northern Argentina. Overall, this hurt Argentina's credibility and the resulting lack of trust weakens a system reliant on accurate and timely self-reporting to the OIE.

Furthermore, the OIE could not incentivize the United States to reassess Argentina's FMD status more quickly so as to reopen its import market. This failure could also undermine the system if an importing country's reluctance makes the exporting country less likely to report an FMD occurrence in the first place - hoping it does not turn into an outbreak and the exporter gets discovered because it is worried about being shut out of foreign markets for an excessive period of time.

A separate information asymmetry made obvious by this dispute occurs after an outbreak and concerns about whether a beef-exporting country is truly FMD-free. In this case, the asymmetry is between Argentina's government and the rest of the world. As the OIE makes clear, this information is critical and relevant because FMD can spread across borders through international commerce in both cattle and beef products.

There are two main problems with the current system of incentives. First, it places most of the costs of determining whether the exporting country (in this case Argentina) is FMD-free on the importing country (the United States) although most of the benefits of being deemed FMD-free would be enjoyed by 
the exporting country (Argentine beef producers). This overincentivizes the exporting country both to shield information about outbreaks and to potentially request FMD-free status even when the designation is not warranted, because there are benefits from the status and no explicit costs to the exporter in requesting the status change. Second, there is no explicit alternative for the OIE or Argentina to incentivize the importing country (the United States) to speed up the costly process of undertaking a new scientific analysis, even if Argentina's truthfulness had not been in question. As this episode illustrates, Argentina's only recourse was to file a formal dispute in which it would eventually be authorized to retaliate (impose costs on the United States) if the importer refused to comply.

One proposal is to institutionalize a system that would call for the exporting and importing countries to share the burden of the costs for such inspections. If the act of requesting an inspection entailed some cost to the exporting country, this would help alleviate the information asymmetry problem of the exporter requesting foreign inspections too soon-i.e., before it is actually FMD-free. When reputational effects are important, an apparent abuse of asymmetric information can also hurt the credibility of a country's regulators with the outside world. While more analysis is needed to fully evaluate such a proposal, the intuition is that it would work like a deductible in an insurance contract. Under moral hazard, sharing the cost burden may help to better align the incentives of the importing and exporting countries.

\section{Additional issues raised in the Panel Report}

\subsection{Discrimination}

Like the rest of the WTO agreements, the SPS Agreement (article 2.3) contains provisions prohibiting arbitrary or unjustifiable discrimination between WTO members where similar conditions prevail.

Argentina claimed that the US measures arbitrarily discriminated against Argentina both substantively and procedurally. The first substantive claim of discrimination compared US imports from Uruguay with those from Northern Argentina, since both regions had FMD outbreaks at roughly the same time, both were recognized by the OIE as FMD-free where vaccination is practiced, and both had similar physical situations and institutional structures for dealing with FMD. The second claim compared Chile and Brazil's Santa Catarina for imports of animal products from Patagonia since all three regions had their last FMD outbreaks around the same time and the OIE recognized all as FMD-free where vaccination is not practiced.

Argentina's procedural claims were that the United States maintained a prohibition on imports from Northern Argentina and Patagonia for more than a decade while other WTO members were given risk assessments quite rapidly after outbreaks and were 'given import permission accordingly'. Argentina specifically 
cited Uruguay, which had an FMD outbreak in 2001 but was allowed to export beef to the United States less than two years later, in 2003; the United Kingdom is on the APHIS list of FMD-free regions despite outbreaks in 2000-2001 (same as Argentina) and again in 2008; Japan is likewise on the list despite an outbreak in 2010, which was followed by a risk assessment just one year after the outbreak.

The United States contended that the conditions in Argentina were not similar to those in Uruguay, Santa Catarina, or Chile, citing differences in the size of both the geographical area and the herds in the various regions, the geography and length of borders over which FMD could be spread, the volume of veterinary resources available to check for and treat FMD, and the recent FMD history. The United States also emphasized that Argentina intentionally kept the full extent of the 20002001 FMD outbreaks confidential, whereas Uruguay promptly reported its outbreaks. The United States rejected OIE recognition as sufficient to conclude that similar conditions prevailed in the various regions because the OIE did not take into account whether a region accepted imports from FMD-infected areas, nor its veterinary capacity to detect, prevent, and control FMD.

The Panel did a three-part analysis of Argentina's claims of discrimination. The first assessed whether similar or identical conditions prevail between the two regions. The second examined whether the US measures discriminate between the two regions. The third considered whether the discrimination is arbitrary or unjustifiable. The Panel found in the affirmative for two of Argentina's claims of discrimination, but determined that Argentina had not demonstrated that similar conditions prevail between Northern Argentina and Patagonia compared to either the United Kingdom or Japan and hence found no violation of article 2.3 for the UK and Japan claims.

For the first part of the analysis, the Panel stated that the test for similar conditions was whether the risk of FMD introduction posed by imports from two regions and their ability to meet the US Appropriate Level of Protection (ALOP) if subject to comparable mitigating protocols are the same. The Panel recognized that finding similar conditions in two countries required an assessment not only of disease prevalence at a given point in time but also of the 'credibility' of the sanitary measures in place to prevent and control FMD, including veterinary capacity and infrastructure. In assessing whether any discrimination was 'arbitrary or unjustifiable', the Panel considered whether the distinction between the two sets of imports 'bears a rational connection to the objective' of the measures. For both of the claims where the Panel found discrimination, one key factor was its finding of 'undue delay', suggesting that procedural discrimination can affect a determination of substantive discrimination.

The Panel's analysis raises the question of just how similar conditions have to be for a claim of discrimination to prevail. Obviously, in the SPS context, conditions are almost never going to be identical, as the size of the land, number and concentration of animals, and number of veterinarians will always vary from state to state and region to region. In this case, the variance with Uruguay was arguably 
substantial, yet the Panel found similar enough conditions to warrant a finding of discrimination.

\subsection{Regionalization}

This dispute, like a number of recent SPS cases, raises the issue of how and when importing countries must 'adapt' to the regional conditions of an exporting country, including pest- or disease-free areas, ${ }^{18}$ as addressed in both article 6 of the SPS Agreement and the OIE Terrestrial Code. Article 6 in particular places the burden on importing countries to recognize regions or areas that are diseasefree, specifying some of the factors to be considered in such a determination, and requires exporting members that claim such regions to provide evidence of their disease-free status.

Argentina contended that the US refusal to recognize Patagonia as FMD-free or to permit imports of animals or animal products from Patagonia constituted a violation of article 6.1. It claimed that the United States failed to take into account the fact that Patagonia South has been FMD-free since 1976 and Patagonia North since 1994; the FMD eradication and control programs put in place by SENASA; and the criteria and guidelines developed by the OIE, which had recognized the FMD-free status of Patagonia South in 2002 and Patagonia North in 2007.

The United States claimed that it was in the process of adjusting its measure when the Panel was established, as APHIS was still engaged in information exchanges with SENASA and was uncertain as to whether Argentina objectively demonstrated that Patagonia was, and was likely to remain, FMD-free. The United States rejected Argentina's claim that the OIE FMD determination constituted 'criteria or guidelines' under article 6.1. It argued that its regulations meet the criteria of article 6.2 but that once Argentina sought US recognition of Patagonia as FMD-free and the process of evaluating that claim began, the existing US ban on imports was transformed into a provisional measure under SPS article 5.7, which requires that the United States review its measure within a reasonable period of time. The United States claimed it was doing just that when the Panel was established.

The Panel found that the United States had indeed violated article 6.1, noting that APHIS itself was satisfied that it had sufficient information about the FMD situation in Patagonia to conclude its review in $2009 .{ }^{19}$ As a result, the Panel found both that the United States had not completed its review without undue

18 This is also an issue in the ongoing Russia-Pigs (EU) dispute. Several legal-economic issues concerning regionalization are illustrated in the India-Agricultural Products dispute (Bown and Hillman, 2016).

19 The Panel specifically noted that after the 2009 site visit APHIS did not request any additional information from SENASA about the FMD situation in Patagonia; that on 27 April 2009, APHIS sent a letter to SENASA stating that no additional information was required; and that in June and October 2011 the United States stated in meetings of the SPS Committee that APHIS had concluded that imports from Patagonia presented a negligible risk of FMD. 
delay, in violation of article 8 and annex $\mathrm{C}$, and that it had not reviewed the 'provisional' measure within a reasonable period of time (in keeping with article 5.7).

\subsection{Special consideration for developing countries}

Argentina claimed that, under article 10.1 of the SPS Agreement, the United States must give developing countries priority in the queue for inspections, risk assessments, and rulings. Argentina pointed out that the United States had acted with alacrity in reopening access to the US market for beef from the United Kingdom and Japan, while failing to act on Argentina's request for more than nine years, thereby violating article 10.1. The United States claimed that Argentina had never identified any particular needs related to its status as a developing country and therefore could not now claim that the United States had failed to address such unidentified needs.

The Panel started by stating that article 10.1, notwithstanding its somewhat vague 'take account of' language, creates an enforceable obligation on the United States, but largely agreed with the United States. In doing so, the Panel subtly shifted the burden of proof from prior reports that had placed the burden on the developing country to prove its claim that the importing country did not take account of developing-country members' needs (as in EC-Approval and Marketing of Biotech Products). In this case, the Panel expressly provided for a shift in the burden to the importing country to show how it took account of the special needs of the developing country - if the developing country can demonstrate that its special needs were clearly identified and can show a lack of consideration for those special needs.

Argentina claimed that its special need for priority access to the approval process was communicated to the United States but that the latter failed to give Argentina speedier processing. The Panel ruled that article 10.1 and the phrase 'take account of' do not mandate always putting developing countries at the front of the line for risk assessments since importing countries must balance a wide variety of interests in determining when and how to conduct inspections and risk assessments.

\section{Conclusion}

This dispute is the 24th involving trade in cattle-related products (dairy, beef, hides, etc.), indicating the significance of trade frictions in this sector, with SPS measures in particular often having a dramatic impact on trade.

Argentina's global exports of beef fell by more than $80 \%$ in the years after its FMD outbreaks in 2000. While trade with a number of Argentina's partners was restored fairly quickly once the FMD outbreaks ceased and the disease was under control, the United States maintained its ban on imports of Argentine beef for nearly ten years after Argentina requested that it be lifted and for nearly seven years after the last outbreak of FMD was detected anywhere in Argentina. This led Argentina to initiate a WTO dispute with the United States in 2012. 
The Panel found that the United States had not completed its procedures without 'undue delay' (despite the lack of any firm timelines in the SPS Agreement), and that contributed to findings of additional violations: the extended US ban was not based on international standards or on a risk assessment, it was discriminatory, and it was not applied in accordance with the SPS Agreement.

However, the Panel ducked one of the difficult questions raised in this case: If the OIE designates a country or region as FMD-free, does that constitute an international standard that other WTO members must recognize? Does it create any form of rebuttal presumption in favor of recognition?

The US-Animals dispute also highlights that problems remain under the current system because of information asymmetries at the intersection of infectious animal diseases and international trade. As the importing country maintaining trade controls, the burden was on the United States to carry out the necessary procedures to determine whether Argentina had returned to FMD-free status. Yet the United States had little economic incentive to do so and it had considerable distrust in the information that the Argentine government was publicly reporting. This last point appears well justified; the evidence clearly revealed that Argentina was providing inaccurate announcements about the outbreak, spread, and containment of the disease. Yet Argentina's behavior is largely consistent with the basic economic theory behind information asymmetries and market failures: In the presence of possible FMD outbreaks, exporting countries are overincentivized to claim that they are disease-free - either by not reporting an outbreak or by prematurely reporting its successful resolution - even when they are not.

In light of the importance of both infectious diseases and trade in animal products, reconsideration of the national policies and global institutions tasked with creating the right incentives is in order. A partial reallocation of the cost burden of exporter recertification after a disease outbreak - from the importing country to the exporting country - may better incentivize globally efficient behavior by farmers as well as exporting and importing country governments.

\section{References}

Akerlof, George A. (1970), 'The Market for “Lemons”: Quality Uncertainty and the Market Mechanism', Quarterly Journal of Economics, 84(3): 488-500.

APHIS (Animal and Plant Health Inspection Service) (2016a), Regions that APHIS has declared free of foot-and-mouth disease, last modified October 26, 2015', https://www.aphis.usda.gov/aphis/ourfo cus/animalhealth/animal-and-animal-product-import-information/import-live-animals/ct_foot_and_ mouth_and_rinderpest (accessed on 25 August 2016).

(2016b. About APHIS. Available at https://www.aphis.usda.gov/aphis/banner/aboutaphis/ SA_Overview, accessed on August 3.

Bown, C. P. and R. Brewster (forthcoming), 'US-COOL Retaliation: The WTO's Article 22.6 Arbitration', World Trade Review.

Bown, C. P. and J. A. Hillman (2016), 'Bird Flu, the OIE, and National Regulation: The WTO's IndiaAgricultural Products Dispute', World Trade Review, 15(2): 235-257. 
Bown, C. P. and K. M. Reynolds (2015), 'Trade Flows and Trade Disputes', Review of International Organizations, 10(2): 145-177.

Bown, C. P. and J. P. Trachtman (2009), 'Brazil - Measures Affecting Imports of Retreaded Tyres: A Balancing Act', World Trade Review, 8(1): 85-135.

Gramig, B. M., R. D. Horan, and C. A. Wolf (2009), 'Livestock Disease Indemnity Design: When Moral Hazard Is Followed by Adverse Selection', American Journal of Agricultural Economics, 91(3): 627-41.

Greene, J. L. (2015), 'Country-of-Origin Labeling for Foods and the WTO Trade Dispute on Meat Labeling', Congressional Research Service Report 7-5700, 8 December.

Hoekman, B. and J. P. Trachtman (2010), 'Continued suspense: EC-Hormones and WTO disciplines on discrimination and domestic regulation Appellate Body Reports: Canada/United States - Continued Suspension of Obligations in the EC-Hormones Dispute, WT/DS320/AB/R, WT/DS321/AB/R, adopted 14 November 2008', World Trade Review, 9(1): 151-80.

Horn, H. and J. H. H. Weiler (2003), European Communities - Measures Affecting Asbestos and AsbestosContaining Products, in H. Horn and P. C. Mavroidis (eds.), The WTO Case Law of 2001, Cambridge: Cambridge University Press, pp. 14-41.

Howse, R. L. and H. Horn (2009), 'European Communities - Measures Affecting the Approval and Marketing of Biotech Products', World Trade Review, 8(1): 49-83.

Marceau, G. and J. Trachtman (2006), 'A Map of the World Trade Organization Law of Domestic Regulation of Goods', in G. A. Bermann and P. C. Mavroidis (eds.), Trade and Human Health and Safety, Cambridge: Cambridge University Press.

Neven, D. J. and J. H. H. Weiler (2006), 'Japan-Measures Affecting the Importation of Apples (AB-20034): One Bad Apple?', in H. Horn and P. C. Mavroidis (eds.), The WTO Case Law of 2003: The American Law Institute Reporters' Studies, Cambridge: Cambridge University Press, pp. 280-310.

Rich, K. M. (2005), Animal Diseases and the Cost of Compliance with International Standards and Export Markets: The Experience of Foot-and-Mouth Disease in the Southern Cone, Agriculture and Rural Development Discussion Paper, Washington, DC: World Bank.

Wolf, C. A. (2013), Livestock Disease Indemnity Design: Considering Asymmetric Information, OECD working paper, Paris: Organization for Economic Organization and Development. 